\title{
Graphene/Gold Nanocomposites-Based Thin Films as an Enhanced Sensing Platform for Voltammetric Detection of $\mathrm{Cr}(\mathrm{VI})$ Ions
}

\author{
Chella Santhosh, Murugan Saranya, Rajendran Ramachandran, Sathiyanathan Felix, \\ Venugopal Velmurugan, and Andrews Nirmala Grace
}

Centre for Nanotechnology Research, VIT University, Vellore 632 014, India

Correspondence should be addressed to Venugopal Velmurugan; vvelmurugan@vit.ac.in and Andrews Nirmala Grace; anirmalagladys@gmail.com

Received 31 July 2013; Revised 15 November 2013; Accepted 23 December 2013; Published 5 February 2014

Academic Editor: Carlos R. Cabrera

Copyright (C) 2014 Chella Santhosh et al. This is an open access article distributed under the Creative Commons Attribution License, which permits unrestricted use, distribution, and reproduction in any medium, provided the original work is properly cited.

\begin{abstract}
A highly sensitive and selective $\mathrm{Cr}(\mathrm{VI})$ sensor with graphene-based nanocomposites film as an enhanced sensing platform is reported. The detection of chromium species is a challenging task because of the different possible oxidation states in which the element can occur. The sensing film was developed by homogenously distributing Au nanoparticles (AuNPs) onto the twodimensional (2D) graphene nanosheet matrix by electrochemical method. Such nanostructured composite film platforms combine the advantages of AuNPs and graphene nanosheets because of the synergistic effect between them. This effect greatly facilitates the electron-transfer processes and the sensing behavior for $\mathrm{Cr}(\mathrm{VI})$ detection, leading to a remarkably improved sensitivity and selectivity. The interference from other heavy metal ions is studied in detail. Such sensing elements are very promising for practical environmental monitoring applications.
\end{abstract}

\section{Introduction}

Heavy metal ions are paid more attention in environmental, toxicological, pharmaceutical, and biomedical analysis point of view [1-3]. Among those, the detection of chromium is of particular interest owing to the high toxicity of chromium (VI) ions. The detection of chromium species is a challenging task because of the different possible oxidation states of the element. The most common valences are $0,+\mathrm{II},+\mathrm{III}$, and + VI. The two environmentally relevant valence states of chromium, namely, $\mathrm{Cr}(\mathrm{III})$ and $\mathrm{Cr}(\mathrm{VI})$, have a contrasting impact on environment and health. Trivalent chromium is relatively harmless, plays an essential role in biological processes, and is related to human glucose tolerance [4], whereas hexavalent chromium is about 100-1000 times more carcinogenic and toxic [5] because of its high oxidation potential and is limited in groundwater by WHO provisional guideline value of $0.05 \mathrm{mg} \mathrm{L}^{-1}$ (50 ppb) [6]. The main sources of anthropogenic chromium pollution in ground water are plating industries, cooling towers, timber treatment [7], leather tanning, wood preservation, and steel manufacturing [8]. The major toxic effects of $\mathrm{Cr}(\mathrm{VI})$ are chronic ulcers, dermatitis, corrosive reaction in nasal septum, and local effects in the lungs [9].

There are several approaches for the detection of $\mathrm{Cr}(\mathrm{VI})$ ions like atomic absorption spectroscopy (AAS) [10], inductively coupled plasma atomic emission spectrometry (ICPAES) [11], inductively coupled plasma mass spectroscopy (ICP-MS) [12], and colorimetry with 1,5-diphenylcarbazide [13] for the environmental analysis of chromium. To determine the total concentration of chromium, these methods are sensitive and accurate but they are time-consuming and expensive and require sophisticated techniques. Electrochemical methods are chosen for analytical purpose, as they are reliable and sensitive and require less expensive equipment $[14,15]$. Voltammetric methods have been 
described in the literature for the detection of $\mathrm{Cr}(\mathrm{VI})$ using metallic nanoparticles modified carbon screen-printed electrodes [16], pyridinium-based sol-gel film [17], selfassembled monolayer [18], and modified electrodes [19, 20]. Metal nanoparticles have been extensively used in recent years for the development of highly sensitive nanodevices because of their unusual physical and chemical properties. Zayats and coworkers have successfully utilized the nanosized Au particles in the development of versatile biosensors [21]. The electrodeposited Au nanoparticles have been used for the detection of arsenic [22]. However, Au nanoparticles have not been used for the detection of carcinogenic $\mathrm{Cr}(\mathrm{VI})$, because $\mathrm{Au}$ is known to be very sensitive towards $\mathrm{Cr}(\mathrm{VI})$. Considering the importance of the measurement of $\mathrm{Cr}(\mathrm{VI})$ in groundwater, in the present investigation we have utilized Au nanoparticles for the voltammetric detection of $\mathrm{Cr}(\mathrm{VI})$.

Graphene, a single layer of $\mathrm{sp}^{2}$ hybridized carbon atoms packed into a dense honeycomb two-dimensional lattice, has attracted tremendous attention from both experimental and theoretical scientific communities since it was experimentally produced in 2004 [23, 24]. Graphene-based materials hold great promise in fabricating enhanced electrochemicalsensing platforms. However, graphene-based nanocomposite film has never been used for the determination of $\mathrm{Cr}(\mathrm{VI})$. Herein, we report on an ultrasensitive $\mathrm{Cr}(\mathrm{VI})$ sensor by using nanocomposite film of monodispersed Au nanoparticles and graphene as the powerful platform. Uniform AuNPs were homogenously distributed onto the graphene nanosheet matrix, constructing a monodispersed AuNPsbased ensemble. It is worth noting that the as-prepared composite matrix in this work combines the advantages of the graphene nanosheets (unique electrical conductivity and enlarged active surface area) together with AuNPs (extraordinary catalytic activity and good conductivity). This should greatly facilitate the rapid, stable and sensitive measurement of $\mathrm{Cr}(\mathrm{VI})$. The performance of this novel platform for voltammetric detection of $\mathrm{Cr}(\mathrm{VI})$ is investigated in detail. Encouragingly, such a nanostructured composite film offers a remarkably improved sensitivity and selectivity and exhibits fine applicability for the detection of $\mathrm{Cr}(\mathrm{VI})$ in practical water samples.

\section{Materials and Methods}

2.1. Materials. Graphite powder, $\mathrm{HAuCl}_{4} \cdot 4 \mathrm{H}_{2} \mathrm{O}$, polyvinylpyrrolidone (PVP), sodium nitrate, sulphuric acid (98\%), potassium permanganate, hydrogen peroxide $(30 \%)$, and hydrazine hydrate (35\%), chitosan were purchased from SDFine, India. All reagents were of analytical reagent grade and were used without further purification. All the reagents were prepared using Milli-Q water.

2.2. Synthesis of Graphene Oxide. Graphene oxide was prepared from natural graphite powder using modified Hummers Jr. and Offeman method [25] as follows. In a typical synthesis, $1 \mathrm{~g}$ of graphite and $1 \mathrm{~g}$ of $\mathrm{NaNO}_{3}$ were mixed with $46 \mathrm{~mL}$ of $\mathrm{H}_{2} \mathrm{SO}_{4}(98 \%)$ in a $250 \mathrm{~mL}$ flask in an ice bath. To it, $6 \mathrm{~g}$ of $\mathrm{KMnO}_{4}$ was slowly added at below $20^{\circ} \mathrm{C}$ with vigorous stirring. The resulting mixture was stirred at room temperature for $1 \mathrm{~h}$, diluted with $70 \mathrm{~mL}$ of water, and stirred at $95^{\circ} \mathrm{C}$ for $2 \mathrm{~h}$. Then, the mixture was further diluted with $100 \mathrm{~mL}$ of water and deoxidized with $7 \mathrm{~mL}$ of $\mathrm{H}_{2} \mathrm{O}_{2}$ (30\%). Finally, the product formed in the solution was separated out by centrifugation at $7000 \mathrm{rpm}$ and then repeatedly washed with $600 \mathrm{~mL}$ of water for six times until the $\mathrm{pH}$ of supernatant was neutral. The graphene oxide (gray powder) was obtained by drying the product in vacuum at $60^{\circ} \mathrm{C}$ for $24 \mathrm{~h}$.

2.3. Preparation of PVP Protected Grapheme. PVP protected graphene is prepared from the as-synthesized graphene oxide. In a typical synthesis, $100 \mathrm{mg}$ of graphene oxide was dispersed in $50 \mathrm{~mL}$ of water containing $2.5 \%$ polyvinylpyrrolidone (PVP). Then, $0.2 \mathrm{~mL}$ of hydrazine hydrate $(35 \%)$ in water was added with a subsequent addition of $1.5 \mathrm{~mL}$ aqueous ammonia (28\%) into the graphene oxide solution. After the solution was held at $95^{\circ} \mathrm{C}$ for $1 \mathrm{~h}$, the product formed in the solution was separated by centrifugation and washed with $100 \mathrm{~mL}$ of water for six times. Finally, graphene was obtained by drying the product in vacuum at $60^{\circ} \mathrm{C}$ for $24 \mathrm{~h}$.

2.4. Fabrication of the Au@Graphene Films. Ultrasonic agitation for ca.30 min was used to disperse $4 \mathrm{mg}$ of PVP protected graphene nanosheets into $0.5 \mathrm{~mL}$ of $0.03 \mathrm{mgm}^{-1}$ chitosan. Prior to the surface modification, the bare Au electrode was polished carefully with $0.05 \mu \mathrm{m}$ alumina powder, rinsed with deionized water, followed by sonication in acetone and doubly distilled water successively, and dried under nitrogen. $20 \mu \mathrm{L}$ of the resulting chi-graphene dispersion was dropped onto the surface of the cleaned gold electrode with a geometric surface area of $0.0707 \mathrm{~cm}^{2}$ and was dried at room temperature (labeled as chi-graphene/Gold Electrode). Further modification of AuNPs onto chi-graphene/gold electrode was conducted by CV scanning from 0.2 to $1.0 \mathrm{~V}$ in $0.1 \mathrm{M} \mathrm{KCl}$ solution containing $2 \mathrm{mM} \mathrm{HAuCl}_{4}$ at a scan rate of $50 \mathrm{mV} / \mathrm{s}$ for 8 cycles. After modification, the electrode (denoted as AuNPs-chi-graphene/Gold Electrode) was thoroughly rinsed with water and kept at room temperature for further use. The amount of Au loaded on the graphene matrix was calculated to be $0.746 \mathrm{wt} \%$.

2.5. Instruments. The phase and the crystallographic structure were identified by X-ray diffraction (XRD, Philips X'Pert Pro, $\mathrm{Cu}-\mathrm{K} \alpha: \lambda=0.1540598 \mathrm{~nm}$ ). The particle size and morphology of the products were studied by FE-Scanning Electron Microscopy (FE-SEM) (HITACHI SU6600 SEM). FTIR spectra were recorded for studying the functional groups using $\mathrm{KBr}$ disks on a Shimadzu affinity spectrophotometer.

2.6. Electrochemical Setup. Electrochemical measurements were performed using $\mathrm{CHI} 660 \mathrm{C}$ model using a threeelectrode type electrochemical cell. A three-electrode system was employed with a SCE-sat. $\mathrm{KCl}$ as reference electrode, a platinum wire as counter electrode and AuNPs-chi-graphene modified $\mathrm{Au}$ as working electrode respectively. 


\section{Results and Discussion}

3.1. XRD Spectrum. X-ray diffraction (XRD) pattern of raw graphite and graphene oxide is shown in Figure 1. In Figure $1(\mathrm{a})$, raw graphite has XRD diffraction peaks at 26.4, 44.3 , and $54.5^{\circ}$ corresponding to the hexagonal lattice of (002), (101), and (004) planes with an interplanar distance of $0.338 \mathrm{~nm}$. After oxidation, the intense (002) peak of graphite powder disappears and an additional peak at $10.94^{\circ}$ is observed, which corresponds to the (001) diffraction peak of graphene oxide. Graphite powder shows a sharp (002) peak at $26.4^{\circ}$ with a typical interspacing of $3.38 \mathrm{~A}^{\circ}$; however, it is found that $\mathrm{GO}$ exhibits a strong peak at $10.94^{\circ}$ corresponding to the (001) interplanar spacing of $8.2 \AA$, suggesting that graphite has been successfully oxidized by modified Hummers Jr. and Offeman method. The increase in interplanar distance in GO might be due to the presence of oxygen, carboxyl, and other functional groups in graphene oxide [26]. Oxidation of graphite leads to the increase in dspacing, which can be attributed to the oxide induced oxygen containing functional groups and inserted water molecules.

3.2. Morphology Characterization. The morphology of the AuNPs-chi-graphene was analyzed by SEM analysis. Figure 2 shows the corresponding FE-SEM image of AuNPs-chigraphene deposited on ITO glass. From the image, it can be seen that the particles are deposited within the graphene matrix. Graphene seems to be crumbled and coiled and within the matrix, particles of Au are seen embedded.

\subsection{Electrochemical Studies}

3.3.1. Electroactivity of the Chromate Species-Electrolyte Analysis. An initial study of the reduction of $\mathrm{Cr}(\mathrm{VI})$ was carried out using cyclic voltammetry at gold $(\mathrm{Au})$ and glassy carbon (GC) electrode materials at $\mathrm{pH} 1$ (CVs not shown). When compared to GC electrode, Au electrode gave good response and because of this $\mathrm{Au}$ electrode was chosen for further investigations. Before probing the chromium detection, bare $\mathrm{Au}$ electrodes were tested by running a CV in two different electrolytes, namely, $0.1 \mathrm{M}$ and $0.01 \mathrm{M} \mathrm{HCl}$. To choose the $\mathrm{pH}$ of the electrolyte, CVs were run in different electrolytes, namely, $0.1 \mathrm{M}$ and $0.01 \mathrm{M} \mathrm{HCl}$. Figure 3 shows the corresponding cyclic voltammetry curves plotted as current versus potential obtained for $0.1 \mathrm{M} \mathrm{HCl}$ and $0.01 \mathrm{M} \mathrm{HCl}$ electrolyte using bare gold $(\mathrm{Au})$ electrode at a scan rate of $50 \mathrm{mVs}^{-1}$. There were not any peaks except for the peak at higher potentials corresponding to the formation of Au oxides. The $\mathrm{CV}$ for $0.01 \mathrm{M} \mathrm{HCl}$ showed a large capacitive current and, in this regard, the detection of $\mathrm{Cr}(\mathrm{VI})$ ions will be uncertain. From the figure, it can be seen that $0.1 \mathrm{M} \mathrm{HCl}$ gave good response and hence $0.1 \mathrm{M} \mathrm{HCl}$ was taken as the standard electrolyte system.

3.3.2. Electrochemical Reduction of Cr(VI) Using Bare Au Electrode. Before probing the role AuNPs-chi-graphene modified electrode, bare Au electrode was checked for $\mathrm{Cr}(\mathrm{VI})$ ions reaction analysis. Figure 4 shows the corresponding cyclic

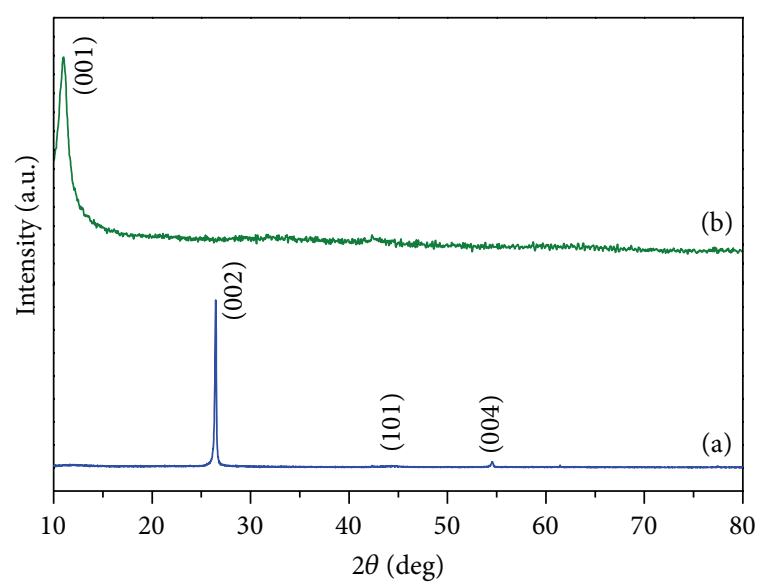

FIGURE 1: XRD pattern for (a) raw graphite and (b) graphite oxide.

voltammetry plotted as current versus potential in $0.1 \mathrm{M}$ $\mathrm{HCl}$ electrolyte containing $200 \mu \mathrm{M} \mathrm{Cr}(\mathrm{VI})$ using bare gold (Au) electrode at a scan rate of $50 \mathrm{mVs}^{-1}$. It can be seen that the response of gold electrode to $\mathrm{Cr}(\mathrm{VI})$ in $0.1 \mathrm{M} \mathrm{HCl}$ gave a well-defined reduction peak at $+0.314 \mathrm{~V}$. The shape of the voltammogram might be preliminarily attributed to an electrochemically reversible process, whilst the absence of corresponding oxidation peak in the potential range studied indicates a chemically irreversible reaction.

\subsection{Electrochemical Reduction of Cr(VI) Using AuNPs-Chi-Graphene/Gold Electrode}

3.4.1. Electrodeposition of Au Nanoparticles on Modified Gold Electrode. Figure 5 shows the CVs during electrodeposition of $\mathrm{Au}$ nanoparticles onto graphene modified $\mathrm{Au}$ electrode in $0.1 \mathrm{M} \mathrm{HCl}$ at a scan rate of $50 \mathrm{mVs}^{-1}$. Electrodepositing $\mathrm{Au}$ nanoparticles on the graphene modified Au electrode will facilitate the uniform dispersion of $\mathrm{Au}$ nanoparticles onto graphene matrix. Figure 5 shows the CV recorded during the course of electrodeposition of $\mathrm{Au}$ nanoparticles. From the figure, it can be clearly seen that a welldefined reduction peak with a peak potential at $+0.34 \mathrm{~V}$ (versus SCE) is observed. This peak corresponds to the $\mathrm{Au}$ oxide/reduction peak, confirming that Au nanoparticles are deposited onto the graphene modified electrodes. The shape of the voltammograms might be preliminarily attributed to an electrochemical reversible process, whilst the absence of corresponding oxidation peak in the potential range studied indicates a chemically irreversible reaction.

3.4.2. Electrochemical Reduction of Cr(VI) on Modified Au Electrode. Figure 6 shows the corresponding cyclic voltammetric run in $0.1 \mathrm{M} \mathrm{HCl}$ containing $200 \mu \mathrm{M} \mathrm{Cr}(\mathrm{VI})$ using AuNPs-chi-graphene modified gold ( $\mathrm{Au}$ ) electrode at a scan rate of $50 \mathrm{mVs}^{-1}$. As can be seen, the response obtained at the modified gold $(\mathrm{Au})$ electrode consists of a peak at $+0.46 \mathrm{~V}$. Comparing both modified and unmodified electrodes, the peak potential is quite good at the modified 


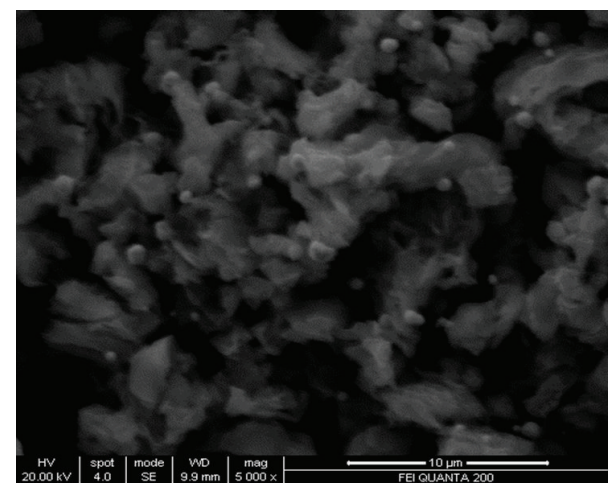

(a)

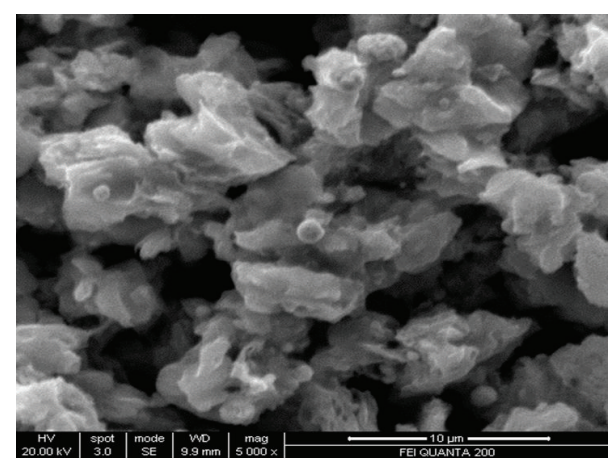

(c)

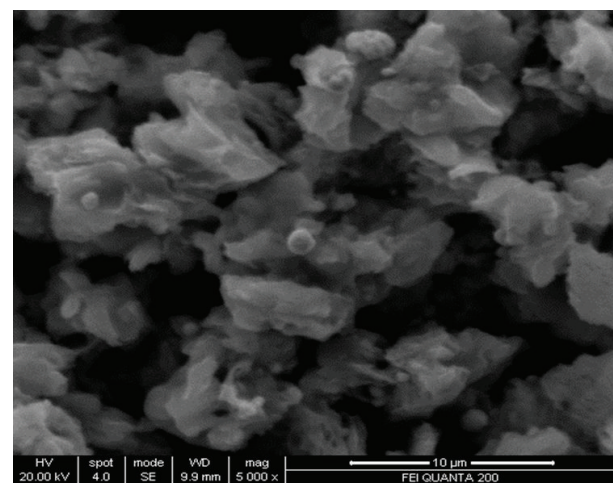

(b)

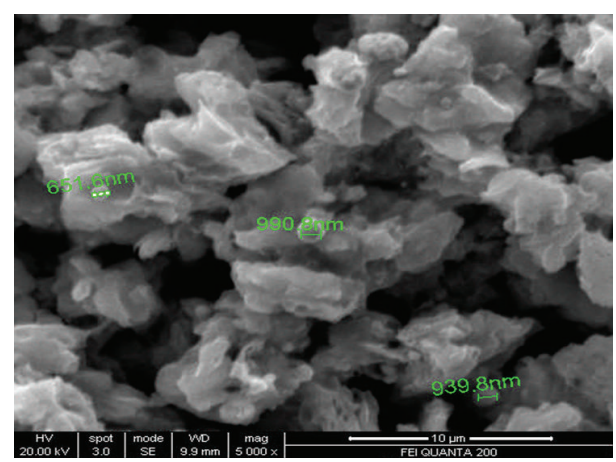

(d)

FIGURE 2: FE-SEM images of AuNPs-chi-graphene deposited on ITO substrates at various magnifications.

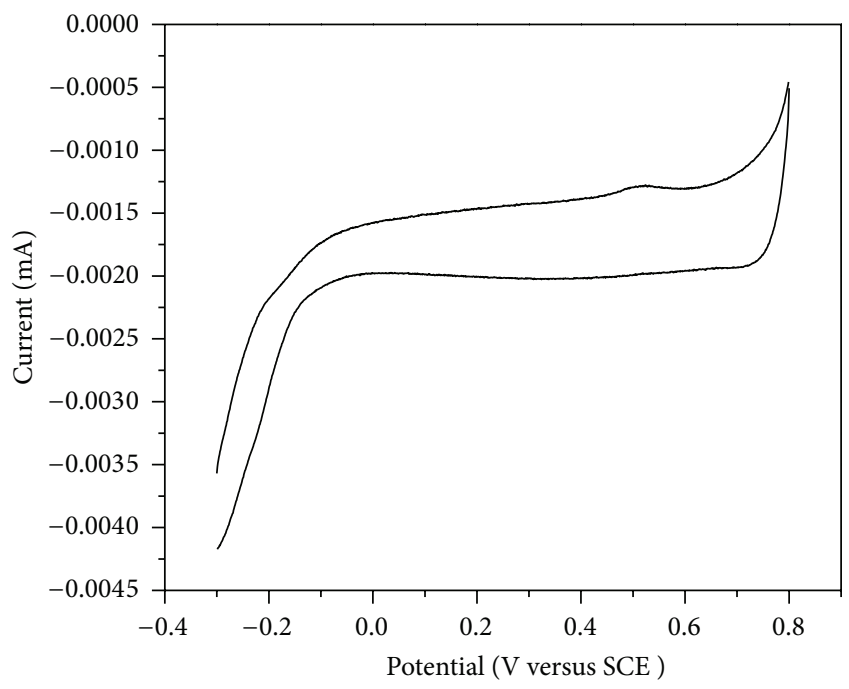

(a)

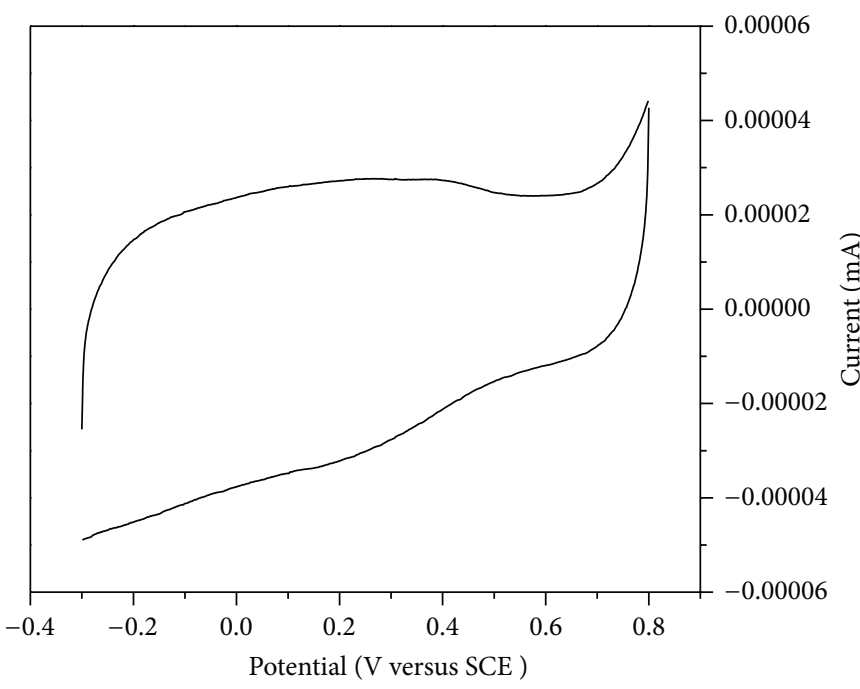

(b)

FiguRE 3: Voltammetric responses of bare gold ( $\mathrm{Au}$ ) electrode in different electrolytes: (a) $0.1 \mathrm{M} \mathrm{HCl}$ and (b) $0.01 \mathrm{M} \mathrm{HCl}$, respectively (scan rate $\left.=50 \mathrm{mVs}^{-1}\right)$.

$\mathrm{Au}$ electrode which increases the sensitivity of hexavalent chromium ions. A comparison of unmodified and AuNPschi-graphene modified Au electrode (Figures 4 and 6) reveals that the reduction is enhanced 100 times in the presence of graphene/gold modified electrode surfaces. Compared to the bare Au electrode, the nanoparticle-modified electrodes exhibited typical voltammetric response for $\mathrm{Cr}(\mathrm{VI})$. The AuNPs-chi-graphene modified Au electrode shows welldefined voltammetric peaks for $\mathrm{Cr}(\mathrm{VI})$ at $0.4 \mathrm{~V}$. The voltammetric response obtained is ascribed to the three-electron reduction of $\mathrm{Cr}(\mathrm{VI})$ to $\mathrm{Cr}$ (III). The unmodified Au electrode shows a reduction peak at $0.3 \mathrm{~V}$. The shift in the reduction 


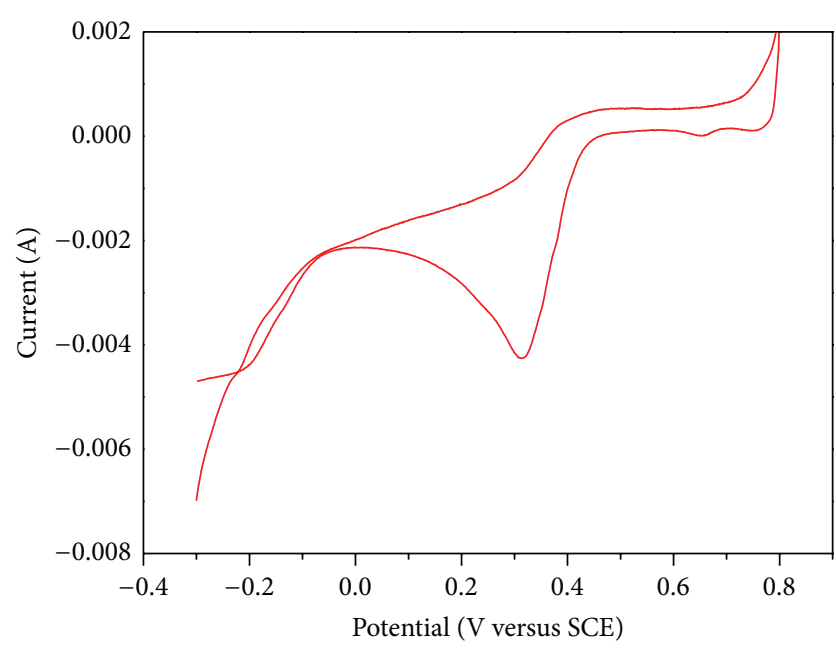

Figure 4: Cyclic voltammograms detailing response of a bare $\mathrm{Au}$ electrode to $200 \mu \mathrm{M} \mathrm{Cr}(\mathrm{VI})$ in $0.1 \mathrm{M} \mathrm{HCl}\left(\right.$ scan rate $\left.=50 \mathrm{mVs}^{-1}\right)$.

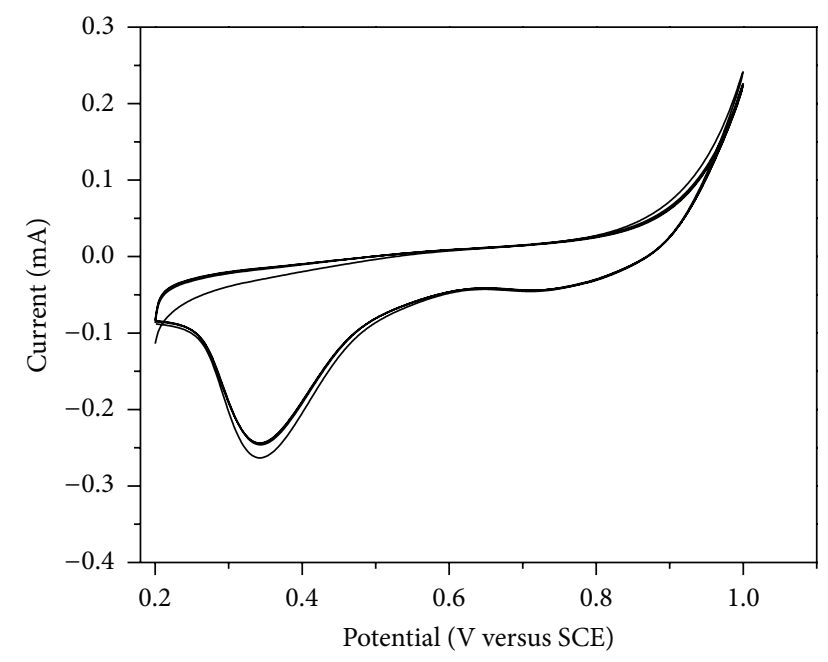

FIGURE 5: Voltammetric responses during the deposition of $\mathrm{Au}$ nanoparticles to chi-graphene/gold electrode in $0.1 \mathrm{M} \mathrm{HCl}$ (scan rate $=50 \mathrm{mVs}^{-1}$ ).

potential and increase in the peak current with respect to the unmodified electrode imply that the nanosized particles on graphene matrix efficiently catalyze the reduction of $\mathrm{Cr}(\mathrm{VI})$.

The voltammetric responses of $50 \mu \mathrm{M}$ hexavalent chromium in $0.1 \mathrm{M} \mathrm{HCl}$ at various scan rates of $10 \mathrm{mV}$, $30 \mathrm{mV}, 50 \mathrm{mV}, 200 \mathrm{mV}$, and $400 \mathrm{mV}$ were examined by cyclic voltammetry using modified gold electrode as shown in Figure 7. These reveal process with a peak potential at $+0.46 \mathrm{~V}\left(100 \mathrm{mVs}^{-1}\right)$, which was found to shift up to $+0.4 \mathrm{~V}$ $\left(400 \mathrm{mVs}^{-1}\right)$ as the scan rate increases. The fact that peak potential is dependent on scan rate suggests that reaction is electrochemically reversible at the Au electrode.

In order to further validate the diffusional nature and, in particular, to test the analytical applicability of the reduction process, the response of $\mathrm{Au}$ electrode to increasing additions of $\mathrm{Cr}(\mathrm{VI})(5-800 \mu \mathrm{M})$ in $0.1 \mathrm{M} \mathrm{HCl}$ was examined. A plot

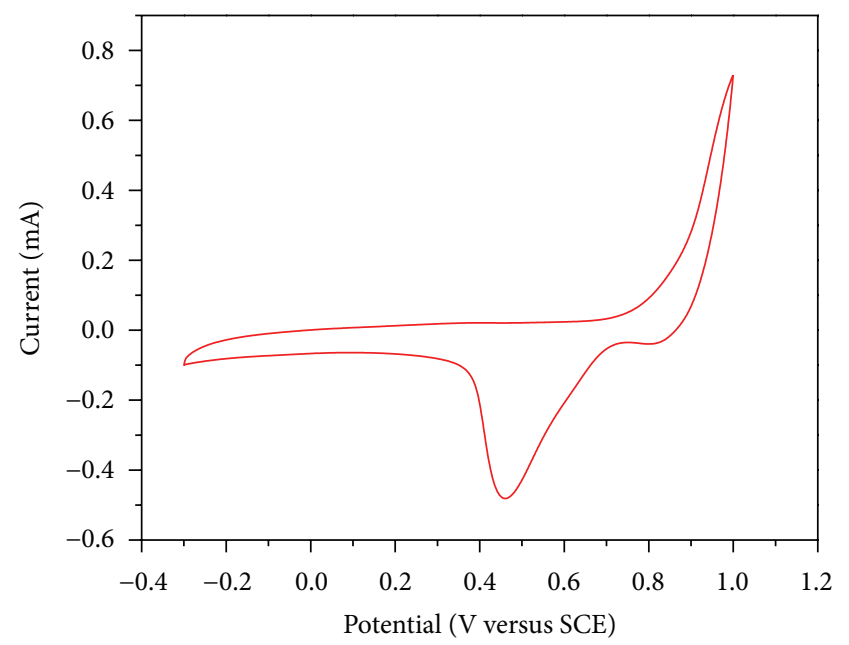

Figure 6: Cyclic voltammogram response of AuNPs-chigraphene/gold electrode to $200 \mu \mathrm{M} \mathrm{Cr}(\mathrm{VI})$ in $0.1 \mathrm{M} \mathrm{HCl}$ (scan rate $=50 \mathrm{mVs}^{-1}$ ).

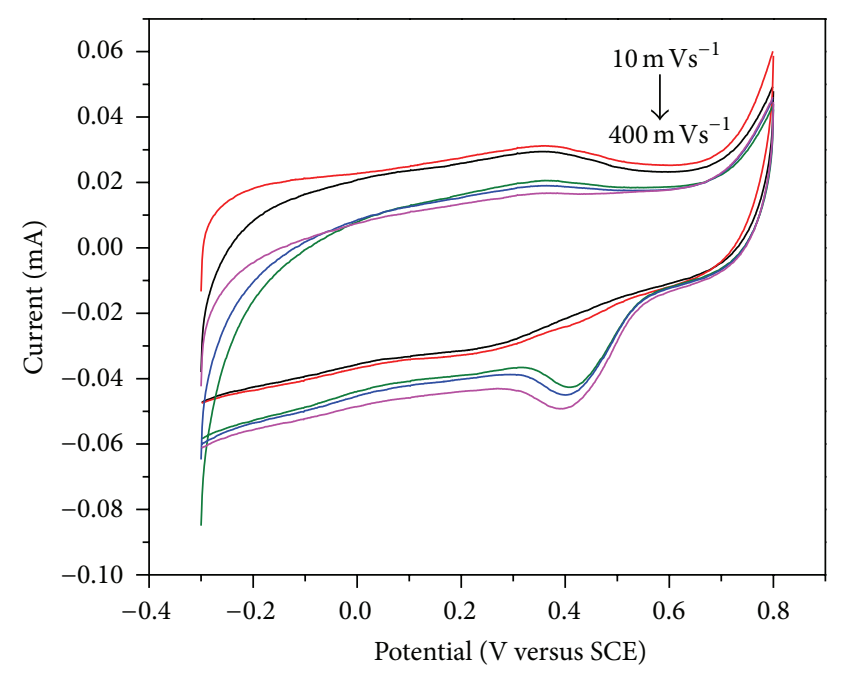

FIGURE 7: Cyclic voltammograms detailing the response to different scan rates $\left(10-400 \mathrm{mVs}^{-1}\right)$ for the solution containing $50 \mu \mathrm{M} \mathrm{Cr}(\mathrm{VI})$ in $0.1 \mathrm{M} \mathrm{HCl}$ at a modified Au electrode.

of the change of reduction peak current as a function of hexavalent chromium added to the solution was found to be linear in the concentration range studied (slope $=1.313$ and $\left.R^{2}=0.9756\right)$ consistent with a diffusion-controlled reaction (see Figure 8).

\section{Conclusions}

The reduction of hexavalent chromium was examined at modified and unmodified gold electrodes. It was found that modified gold electrode (AuNPs-chi-graphene modified $\mathrm{Au}$ electrode) provided good voltammetric responses towards the addition of $\mathrm{Cr}(\mathrm{VI})$ in the electrolyte solutions. It was also verified that, in the presence of grapheme-/gold-based electrodes, the reduction process occurs at more positive 


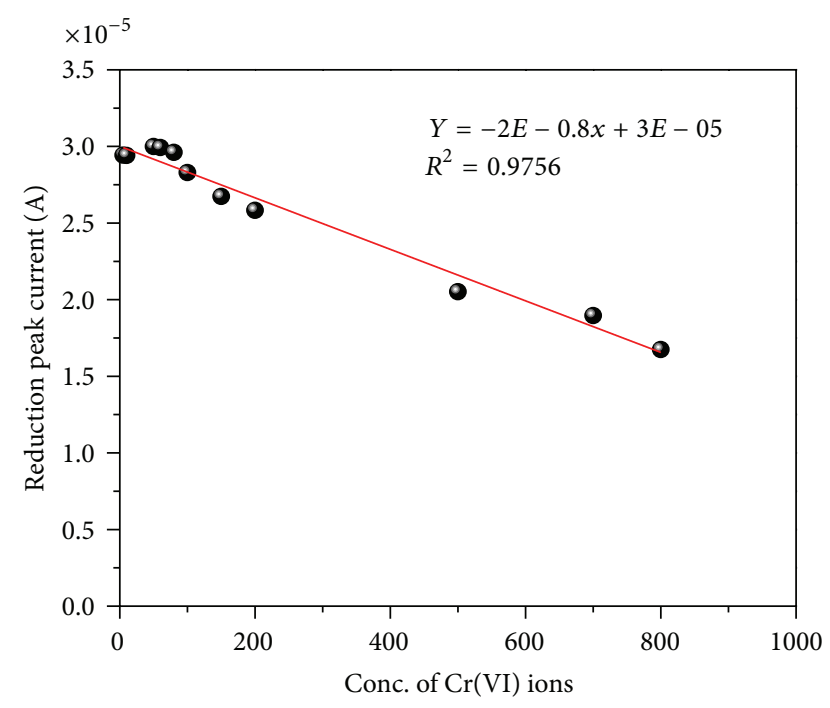

FIGURE 8: A plot of change in reduction current versus hexavalent chromium ion concentration.

potential when compared with that of unmodified gold electrode. The response of the electrode to addition of hexavalent chromium was found to be independent of common environmental interferences, such as $\mathrm{Ni}, \mathrm{Cu}$, and $\mathrm{Cr}$ (III). This investigation proved that the composites are good materials for electrochemical sensing of chromium ions.

\section{Conflict of Interests}

The authors declare that there is no conflict of interests regarding the publication of this paper.

\section{Acknowledgments}

The authors acknowledge the financial support of VIT University, Vellore, for supporting this work under the research associate fellowship. They thank DST-WTI, Government of India, for supporting this work under the Junior Research Fellowship.

\section{References}

[1] J. Johnson, "Mercury summit planned," Chemical \& Engineering News, vol. 76, no. 19, pp. 22-23, 1998.

[2] H. M. Carapuça, S. C. C. Monterroso, L. S. Rocha, and A. C. Duarte, "Simultaneous determination of copper and lead in seawater using optimised thin-mercury film electrodes in situ plated in thiocyanate media," Talanta, vol. 64, no. 2, pp. 566$569,2004$.

[3] K. Honda, M. Sahrul, H. Hidaka, and R. Tatsukawa, "Organ and tissue distribution of heavy metals, and their growthrelated changes in antarctic fish, Pagothenia borchgrevinki," Agricultural and Biological Chemistry, vol. 47, no. 11, pp. 25212532, 1983.

[4] V. Volkovic, Trace Elements Analysis, Taylor and Francis, London, UK, 1975.
[5] B. Liu, L. Lu, M. Wang, and Y. Zi, "A study of nanostructured gold modified glassy carbon electrode for the determination of trace Cr(VI)," Journal of Chemical Sciences, vol. 120, no. 5, pp. 493-498, 2008.

[6] WHO, Guidance for Drinking Water Quality: Recommendations, vol. 1, World Health Organization, Geneva, Switzerland, 3rd edition, 2008.

[7] D. Golub and Y. Oren, "Removal of chromium from aqueous solutions by treatment with porous carbon electrodes: electrochemical principles," Journal of Applied Electrochemistry, vol. 19, no. 3, pp. 311-316, 1989.

[8] R. J. Kieber, J. D. Willey, and S. D. Zvalaren, "Chromium speciation in rainwater: temporal variability and atmospheric deposition," Environmental Science and Technology, vol. 36, no. 24, pp. 5321-5327, 2002.

[9] B. L. Batista, D. Grotto, J. L. Rodrigues, V. C. de Oliveira Souza, and F. Barbosa Jr., "Determination of trace elements in biological samples by inductively coupled plasma mass spectrometry with tetramethylammonium hydroxide solubilization at room temperature," Analytica Chimica Acta, vol. 646, no. 1-2, pp. 2329, 2009.

[10] G. Z. Tsogas, D. L. Giokas, A. G. Vlessidis, and N. P. Evmiridis, "A single-reagent method for the speciation of chromium in natural waters by flame atomic absorption spectrometry based on vesicular liquid coacervate extraction," Spectrochimica Acta B, vol. 59, no. 7, pp. 957-965, 2004.

[11] H. Hotta, K. Yata, K. F. B. Kamarudin et al., "Determination of chromium(III), chromium(VI) and total chromium in chromate and trivalent chromium conversion coatings by electrospray ionization mass spectrometry," Talanta, vol. 88, pp. 533-536, 2012.

[12] N. N. Meeravali and S.-J. Jiang, "A novel cloud point extraction approach using cationic surfactant for the separation and preconcentration of chromium species in natural water prior to ICP-DRC-MS determination," Talanta, vol. 80, no. 1, pp. 173178, 2009.

[13] M. L. Kim, J. D. Stripeikis, and M. B. Tudino, "Hybrid mesoporous materials for on-line preconcentration of $\mathrm{Cr}(\mathrm{VI})$ followed by one-step scheme for elution and colorimetric determination at ultratrace levels," Talanta, vol. 77, no. 3, pp. 1068-1074, 2009.

[14] G. Hanrahan, D. G. Patil, and J. Wang, "Electrochemical sensors for environmental monitoring: design, development and applications," Journal of Environmental Monitoring, vol. 6, no. 8, pp. 657-664, 2004.

[15] E. O. Jorge, M. M. Rocha, I. T. E. Fonseca, and M. M. M. Neto, "Studies on the stripping voltammetric determination and speciation of chromium at a rotating-disc bismuth film electrode," Talanta, vol. 81, no. 1-2, pp. 556-564, 2010.

[16] O. Domínguez-Renedo, L. Ruiz-Espelt, N. García-Astorgano, and M. J. Arcos-Martínez, "Electrochemical determination of chromium(VI) using metallic nanoparticle-modified carbon screen-printed electrodes," Talanta, vol. 76, no. 4, pp. 854-858, 2008.

[17] N. A. Carrington, L. Yong, and Z.-L. Xue, "Electrochemical deposition of sol-gel films for enhanced chromium(VI) determination in aqueous solutions," Analytica Chimica Acta, vol. 572, no. 1, pp. 17-24, 2006.

[18] I. Turyan and D. Mandler, "Selective determination of Cr(VI) by a self-assembled monolayer-based electrode," Analytical Chemistry, vol. 69, no. 5, pp. 894-897, 1997. 
[19] B. K. Jena and C. R. Raj, "Highly sensitive and selective electrochemical detection of sub-ppb level chromium(VI) using nano-sized gold particle," Talanta, vol. 76, no. 1, pp. 161-165, 2008.

[20] C. M. Welch, O. Nekrassova, and R. G. Compton, "Reduction of hexavalent chromium at solid electrodes in acidic media: reaction mechanism and analytical applications," Talanta, vol. 65, no. 1, pp. 74-80, 2005.

[21] M. Zayats, R. Baron, I. Popov, and I. Willner, "Biocatalytic growth of $\mathrm{Au}$ nanoparticles: from mechanistic aspects to biosensors design," Nano Letters, vol. 5, no. 1, pp. 21-25, 2005.

[22] X. Dai, G. G. Wildgoose, C. Salter, A. Crossley, and R. G. Compton, "Electroanalysis using macro-, micro-, and nanochemical architectures on electrode surfaces. Bulk surface modification of glassy carbon microspheres with gold nanoparticles and their electrical wiring using carbon nanotubes," Analytical Chemistry, vol. 78, no. 17, pp. 6102-6108, 2006.

[23] K. S. Novoselov, A. K. Geim, S. V. Morozov et al., "Electric field in atomically thin carbon films," Science, vol. 306, no. 5696, pp. 666-669, 2004.

[24] D. Li, M. B. Müller, S. Gilje, R. B. Kaner, and G. G. Wallace, "Processable aqueous dispersions of graphene nanosheets," Nature Nanotechnology, vol. 3, no. 2, pp. 101-105, 2008.

[25] W. S. Hummers Jr. and R. E. Offeman, "Preparation of graphitic oxide," Journal of the American Chemical Society, vol. 80, no. 6, p. 1339, 1958.

[26] T. Liu, Y. Li, Q. Du et al., "Adsorption of methylene blue from aqueous solution by graphene," Colloids and Surfaces B, vol. 90, no. 1, pp. 197-203, 2012. 

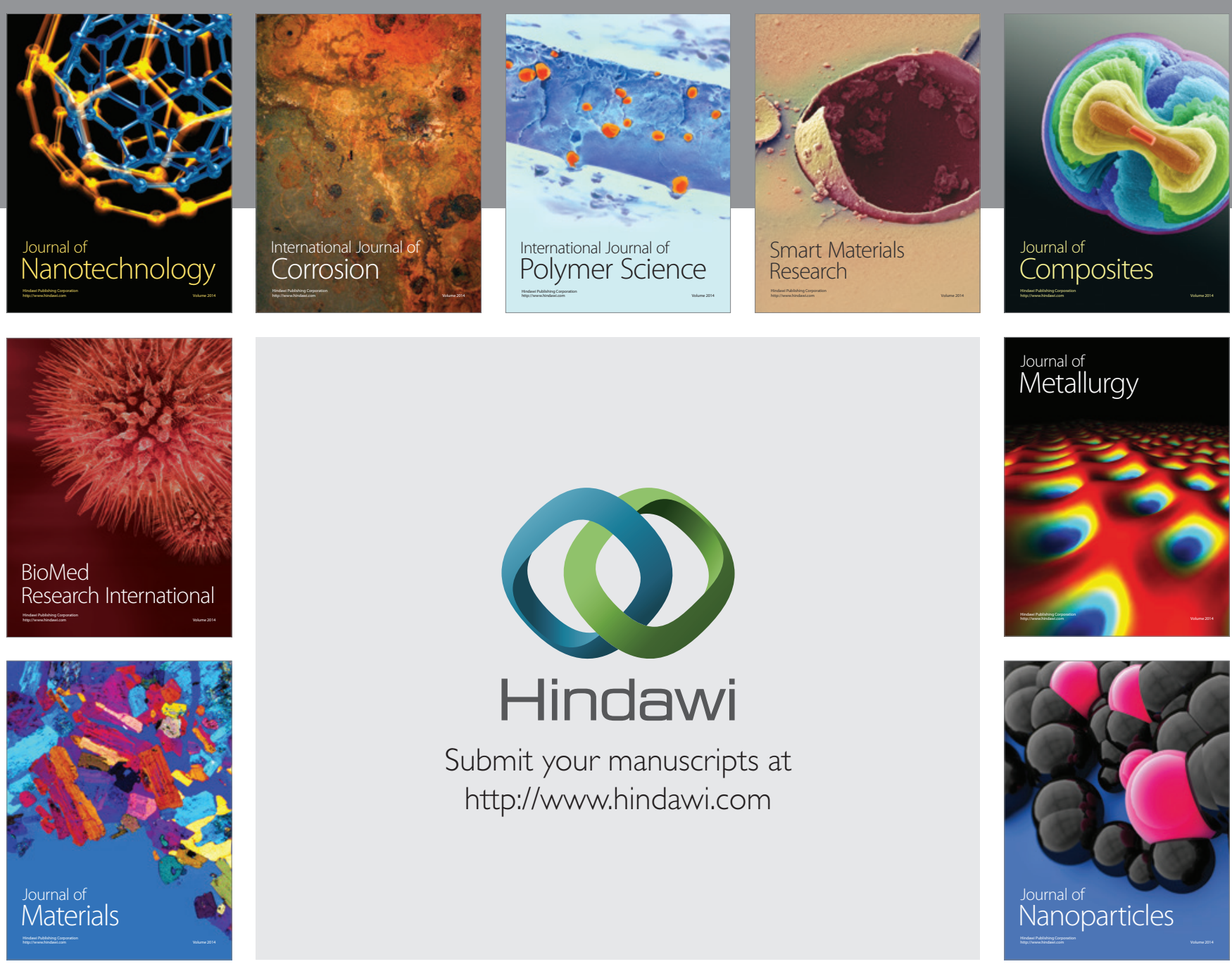

Submit your manuscripts at http://www.hindawi.com
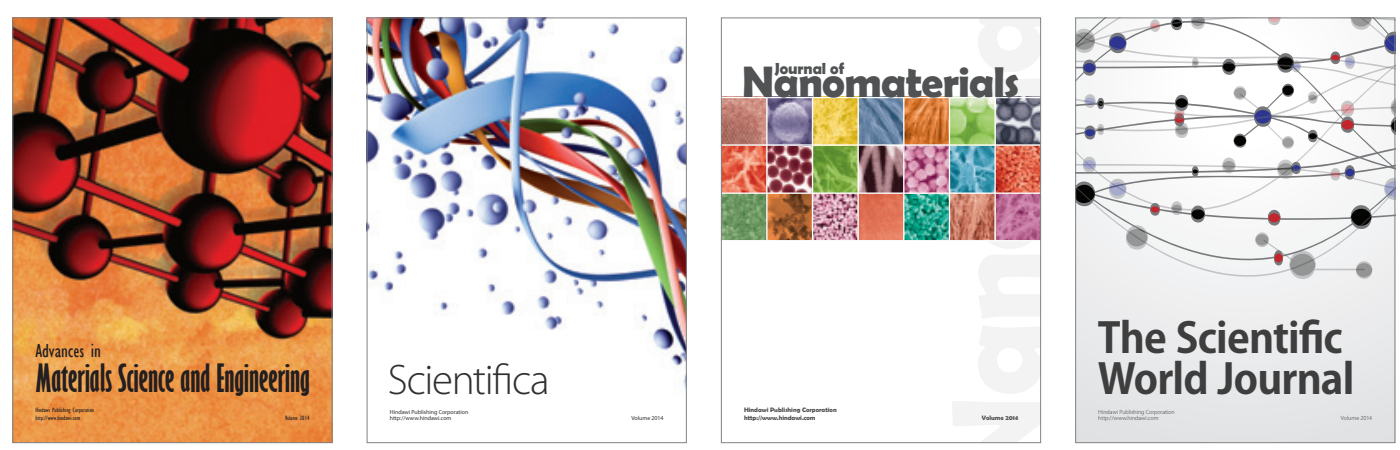

\section{The Scientific World Journal}
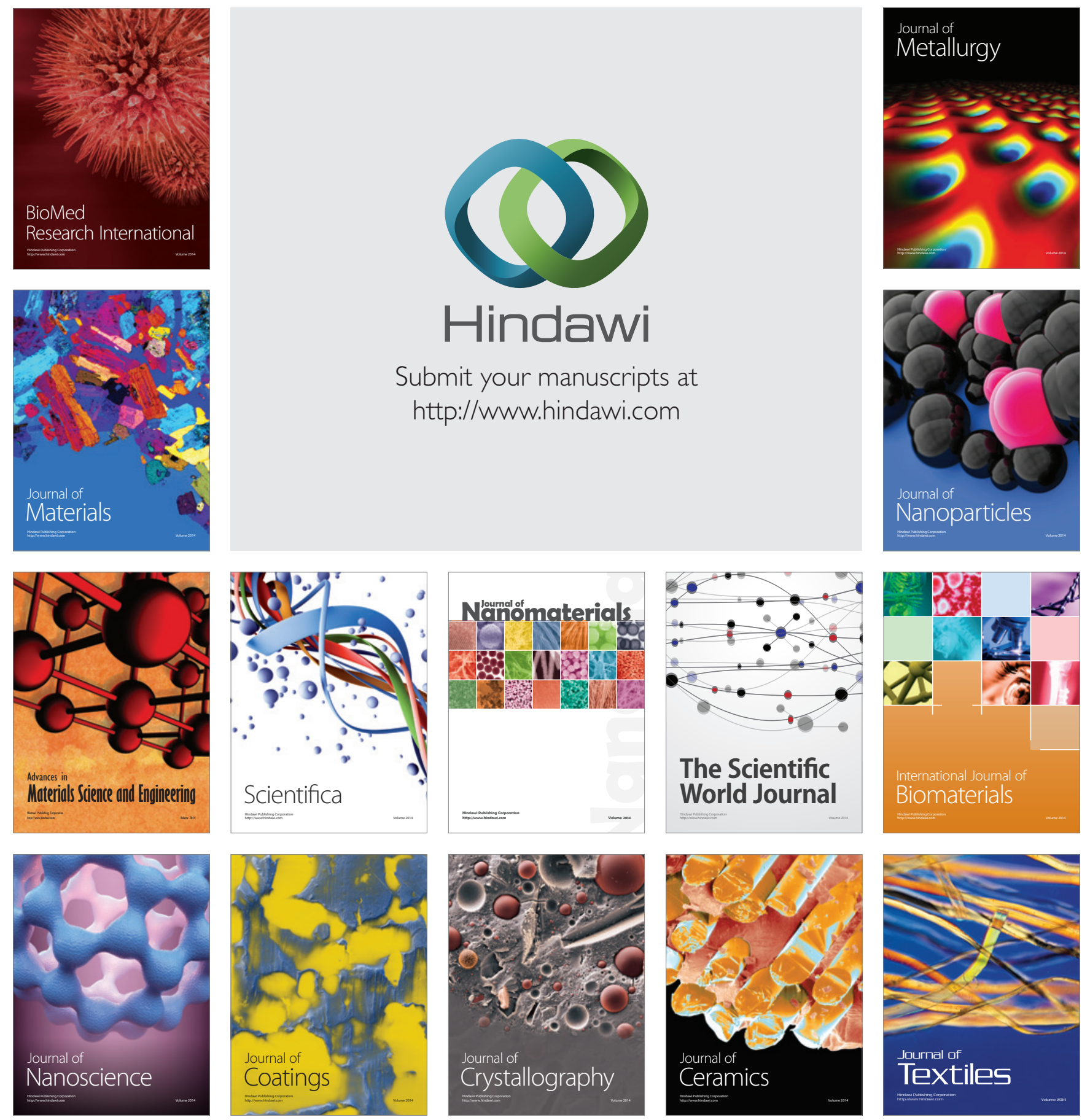